\title{
Transcriptional heterochrony in talpid mole autopods
}

\author{
Constanze Bickelmann ${ }^{1 *}$, Christian Mitgutsch², Michael K Richardson ${ }^{3}$, Rafael Jiménez ${ }^{4}$, \\ Merijn AG de Bakker ${ }^{3}$ and Marcelo R Sánchez-Villagra ${ }^{1 *}$
}

\begin{abstract}
Background: Talpid moles show many specializations in their adult skeleton linked to fossoriality, including enlarged hands when compared to the feet. Heterochrony in developmental mechanisms is hypothesized to account for morphological evolution in skeletal elements.

Methods: The temporal and spatial distribution of SOX9 expression, which is an early marker of chondrification, is analyzed in autopods of the fossorial Iberian mole Talpa occidentalis, as well as in shrew (Cryptotis parva) and mouse (Mus musculus) for comparison.

Results and discussion: SOX9 expression is advanced in the forelimb compared to the hind limb in the talpid mole. In contrast, in the shrew and the mouse, which do not show fossorial specializations in their autopods, it is synchronous. We provide evidence that transcriptional heterochrony affects the development of talpid autopods, an example of developmental penetrance. We discuss our data in the light of earlier reported pattern heterochrony and later morphological variation in talpid limbs.
\end{abstract}

Conclusion: Transcriptional heterochrony in SOX9 expression is found in talpid autopods, which is likely to account for pattern heterochrony in chondral limb development as well as size variation in adult fore- and hind limbs.

Keywords: SOX9 expression, Developmental penetrance, Talpidae

\section{Background}

Talpid moles (Talpidae, Lipothyphla sensu [1]) show a great number of morphological peculiarities in their postcranial skeleton which can be interpreted as being related to their specialized locomotor behavior. Among other modifications, the forelimbs of fossorial talpid moles are enlarged and more robust than the hind limbs (Figure 1A, B). The manus is broad and strong and its palm faces outward (Figure 1A) [2]. Serving for further enlargement of the autopodial area, fossorial talpid moles also bear an extra digit-like structure ('Os falciforme') in both hands and feet (Figure 1A, B) [3]. The molecular evolution and development of these accessory sesamoid bones were recently investigated in the fossorial Iberian mole, Talpa occidentalis, by an analysis of expression patterns of $S O X 9, F g f 8$ and $M s x 2$ in mole autopodia [4]. Analysis of the timing of SOX9 expression showed that

\footnotetext{
* Correspondence: constanze.bickelmann@pim.uzh.ch; m.sanchez@pim.uzh.ch ${ }^{1}$ Paläontologisches Institut und Museum, Universität Zürich, Karl-Schmid-Strasse 4, Zürich 8006, Switzerland

Full list of author information is available at the end of the article
}

the 'Os falciforme' develops later than the true digits and extends into the digital area in spatial relationship with a Msx2 expressing domain [4]. However, such extreme modifications are not present in a sister-taxon of talpid moles, the terrestrial North American least shrew Cryptotis parva (Soricidae sensu [5]), although some species have also invaded a subterranean habitat (Figure 1C, D) [4].

It has been shown that besides internal constraints, functional or ecological factors can drive changes in developmental timing [7]. Many cases of adaptive heterochrony have been reported, indicating that ontogenetic plasticity provides opportunity for adaptive evolution [8]. In recent years, much work has been conducted on limb developmental timing and their potential adaptive significance, for example [9-11].

The relative timing of chondrification and ossification has been studied quantitatively across mammals $[9,10,12,13]$. A quantitative approach is crucial, as in some cases temporal changes in the development seem
C Biomed Central

(c) 2012 Bickelmann et al.; licensee BioMed Central Ltd. This is an Open Access article distributed under the terms of the Creative Commons Attribution License (http://creativecommons.org/licenses/by/2.0), which permits unrestricted use, distribution, and reproduction in any medium, provided the original work is properly cited. 


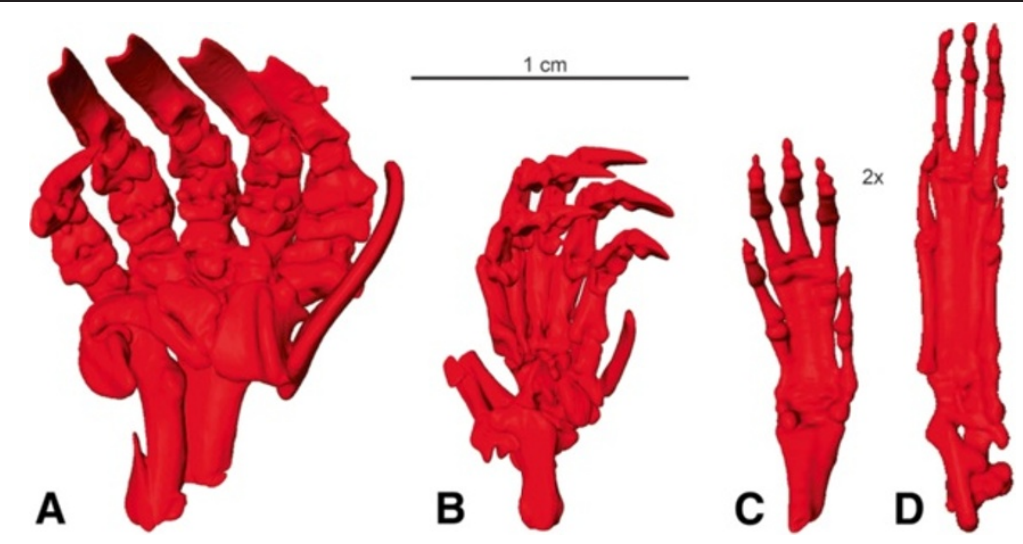

Figure 1 Microtomography scan images of adult Talpa occidentalis (A-B) and Cryptotis parva(C-D). The same models of right hands (A, C) and feet $(B, D)$ were also used in Mitgutsch et al. [4] and Mitgutsch et al. [6].

obvious at first sight, but are not supported by statistical analysis. One prominent example concerns limb chondrification in the bat Rousettus amplexicaudatus, in which differences in the adult size of the limbs appear to be reflected in early stages; a finding which is not supported by quantitative analyses $[12,14]$. These quantitative studies have demonstrated that, with chondrification and skeletogenesis being uncoupled in time across vertebrates, different phases of skeletogenesis have different types of change associated with them $[11,15]$. In Talpa europaea, forelimb development is relatively accelerated compared to that of the hind limb $[9,12]$. This acceleration affects stages extending from the early limb bud to late chondrogenesis $[9,12]$. In fact, changes in the developmental timing have been found in fore- and hind limbs of many tetrapods [9,12]. Among mammals, an accelerated development of the forelimb respective to the hind limb has also been found in hedgehogs, and to a much greater extent in marsupials [12]. In the latter, this heterochrony has been interpreted as an adaptive response to the functional requirements placed on the neonate by its life history, as the extremely altricial neonate must have enough functional maturity to travel to the pouch and process food while completing its development [16]. Concerning the relative timing of ossification, monotremes and moles are the only tetrapods known to date which show late ossification of the stylopod relative to the zeugopod, which further matches their unusual humerus morphology [17].

Transcriptional heterochrony describes temporal changes in or modification of the expression of developmental genes, which can lead to pattern heterochrony [9]. A few cases have been reported in which timing changes in developmental mechanisms between foreand hind limb can cause morphological variation. For example, morphological variation in carpal and tarsal elements of Xenopus laevis might be determined by heterochronic prolongation in Hoxa11 expression [18]. On the other hand, Hoxd12 expression in the chicken wing is delayed compared to the one in the foot, but it is unclear if this transcriptional heterochrony accounts for morphological pattern heterochrony in the wing [19]. Also in the chicken, there is a heterochronically early decline in the expression of Hoxd11/Hoxd12 in the hind limb, in fact, fading before cartilage formation [20]. As the expression of these genes continues after the onset of cartilage formation in the forelimb, the peculiar expression timing in the developing fibula was coupled with the unusual morphology of this bone in the chicken [20].

In order to consider the possible link further between transcriptional and pattern heterochrony, the concept of developmental penetrance may be useful [14]. Developmental penetrance describes the extent to which adaptive changes in the adult phenotype are associated with corresponding changes in early development [14]. For example, pattern heterochrony affecting relatively late stages of chondrification and ossification of certain structures in the skulls of Monodelphis domestica appears to be linked with precocious migration of neural crest cells at earlier stages $[21,22]$. Also, concerning tooth development in mammals, transcriptional changes are known to cause morphological variation [23-25]. These and other examples can be contrasted with others in which such clear connections between early developmental heterochronies and adult anatomy or life history could not be demonstrated [26-29]. Thus, there exist wide differences.

In investigations of heterochrony, markers of chondrogenesis range from early-expressed genes associated with chondrogenesis to histological markers that are applicable later, as for example, Alcian blue uptake. The transcription factor SOX9 plays an important role in chondrogenesis [30]. In particular, it is one of the earliest markers of chondrogenic limb mesoderm and is involved in chondrocyte differentiation [31]. It is expressed in 
condensing chondrogenic cells and is a useful marker for the prospective domains of chondral elements, after initial patterning events have taken place [31-33]. In the chicken, for example, $\mathrm{SOX} 9$ expression provides evidence for the existence of a transient digit I domain in the wing that never progresses to chondrification [34].

Here, we present the temporal and spatial distribution of SOX9 expression in developing lipotyphlan and murid autopodials, in order to test if transcriptional heterochrony leading to morphological pattern heterochrony is present. This will allow us to examine developmental penetrance on limb developmental timing linked to ecological specialization in talpid mole autopods.

\section{Methods}

We analyzed the temporal and spatial distribution of SOX9 expression in developing hands and feet of the fossorial talpid mole Talpa occidentalis, and the terrestrial shrew Cryptotis parva, as well as in the terrestrial mouse Mus musculus (Rodentia). Talpa occidentalis specimens were captured in Santa Fé (Granada province, Spain) under permission granted by the Andalussian Environmental Council. Animal handling followed the guidelines and approval of the University of Granada's Ethical Committee for Animal Experimentation as well as the ATSU (A.T. Still University) Animal Care Committee. Wholemount in situ hybridizations and histological preparations were performed according to Mitgutsch et al. [4]. Digoxigenin-labelled antisense RNA probes were synthesized from plasmids containing PCR products of the major part of the coding sequences of SOX9 of T. occidentalis, using cDNA retro-transcribed from embryonic mRNA of each species as a template [GenBank accession number: HQ260700] [4].

\section{Results}

In Talpa occidentalis, SOX9 expression is apparent in the autopods of an early 17-day embryo (Figure 2A, B). In the hand, it has already reached its peak in that it completely fills every digit. In the most distal parts, SOX9 is expressed the most (Figure 2A). In the foot it is not as strong yet (Figure 2B). The digits are only lightly filled (Figure 2B). In a 18-day embryo, expression of SOX9 has already started fading from proximal to distal in the phalanges of the hand (Figure 2C). In contrast, it has now reached its peak in all digital elements of the foot (Figure 2D). Furthermore, in both hand and foot there is faint SOX9 expression pre-axial to digit one, which is where the accessory sesamoids are located (Figure 2C, D). In a 19-day embryo, SOX9 gene expression is still apparent in digit I and V of the hand, and faint in digits II to IV (Figure 2E). Interestingly, digits I and $\mathrm{V}$ generally seem to be the last digits to ossify in mammals [15]. In the foot it has just started fading from proximal into the outer autopodial region (Figure 2F). SOX9 expression in the accessory sesamoid region in the foot is distinct (Figure 2E, F). In summary, in Talpa occidentalis, we observe an advanced SOX9 expression in the hand compared to the foot.

In the shrew Cryptotis parva, SOX9 expression differs in the temporal distribution from the one seen in the talpid mole. In the hand and foot of a 13.5-day embryo, it has reached its peak (Figure 2G, H). All digits are completely filled (Figure 2G, H). In 15.5-day hand and foot, SOX9 expression is still very strong, but is about to start fading from proximal to distal (Figure 2I, J). In autopods of a 17.5-day embryo, it is in the process of fading in all digital elements from proximal into the outer autopodial region (Figure $2 \mathrm{~K}, \mathrm{~L}$ ). To summarize, in the shrew, SOX9 expression is synchronous in hand and foot.

In the mouse, SOX9 relative timing of expression in the hand and foot is similar to the one seen in the shrew. It is very strong in all digits in the hand and foot of a 12.5-day embryo (Figure 2M, N). Because all digits are completely filled, it has already reached its peak (Figure 2M, N). In the autopods of a 13.5-day embryo, it is still strong in all digital elements, but has already started fading from proximal to distal (Figure 2O, P). In the hand and foot of a 14.5-day embryo, SOX9 expression is in the process of fading simultaneously from proximal to distal (Figure 2Q, R). As in Talpa occidentalis, SOX9 expression is more apparent in digits I and V than digits II to IV (Figure 2Q, R). In summary, as in the shrew, there is synchronous SOX9 expression in the hand and foot in the mouse.

Opposed to observed changes in the temporal SOX9 expression, the spatial distribution is similar in the digits of hands and feet of all investigated species. SOX9 is expressed in all digits as well as the accessory sesamoid regions, marking all areas of prechondral condensations. Fading starts at the proximal base of the digits, proceeding to the distal ends.

\section{Discussion}

Heterochrony in chondral limb development of talpid mole limbs has been reported, with forelimbs showing an advanced development compared to the hind limbs [12]. Among Lipotyphla, this heterochrony was found to be present in terrestrial hedgehogs as well, leading the authors to the assumption that it is a consistent pattern within this clade and not linked to ecological specialization [12]. However, shrews, which are the sister-taxon of talpid moles, were not considered in their study [12], but are included here. In murids, the relative timing has been found to be rather synchronous [12].

Since Talpa occidentalis shows a relative acceleration of SOX9 expression in its hands compared to the feet, whereas in the shrew, which does not display adult 


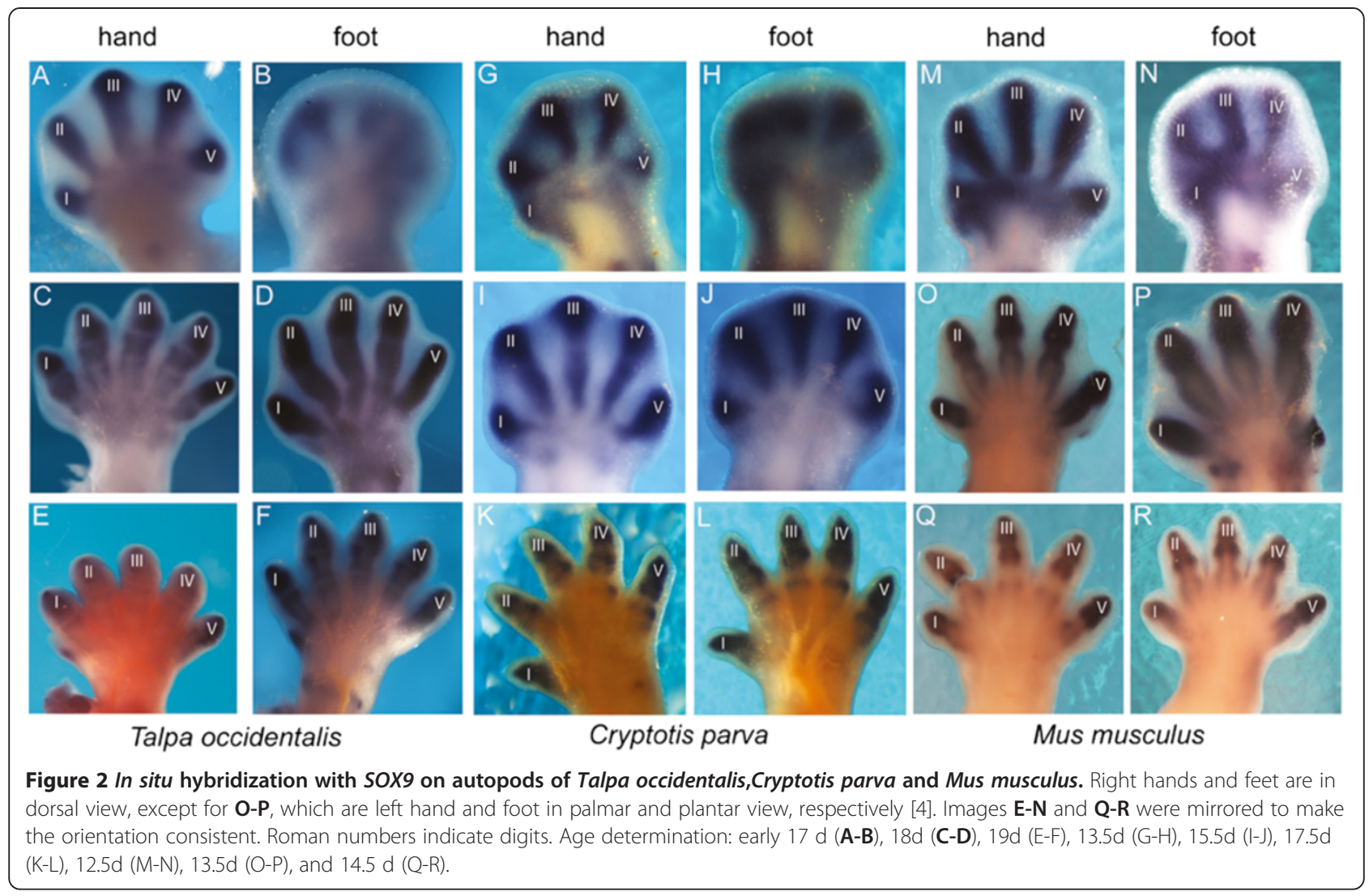

specializations in the autopodial skeleton, it is synchronous, we hypothesize that this transcriptional heterochrony in limbs of the talpid mole accounts for the pattern heterochrony in chondral limb development [12]. Further, it accounts for morphological modification, that is, an enlargement of the autopodial region of the forelimb, in T. occidentalis. It is linked to locomotor behavior and is best explained by the concept of developmental penetrance, describing the finding that selection for an adult trait can cause significant changes already early in developmental mechanisms [14]. Based on comparison with shrew and mouse, we hypothesize that the differential timing of SOX9 expression in the talpid mole is the derived condition. However, since embryos of other, less-specialized talpid moles are currently unavailable for study, it remains unknown at what point in talpid phylogeny since the separation from shrews this change occurred. The separation of shrews and moles is estimated to have occurred between 75.32 and 62.44 million years ago [5]. Both $S O X 9$ expression and chondral autopodial development are synchronous in the mouse [12].

\section{Conclusions}

In the Iberian mole (Talpa occidentalis) expression of SOX9, which is an early marker of chondrification, appears earlier in the hand than in the foot. In contrast, SOX9 expression is synchronous in the sister-taxon of talpid moles, the shrew (Cryptotis parva), and in the mouse (Mus musculus). We hypothesize that this transcriptional heterochrony is related to pattern heterochrony reported in Talpa europaea limb chondrogenesis [7]. Furthermore, it shows that selection for an adult trait can cause changes in developmental mechanisms, a case of developmental penetrance and is linked to ecological specialization [14]. The results contribute to our understanding of the evolution of adaptive morphologies and their underlying genetic mechanisms in mammalian natural mutants (sensu [35]).

\section{Competing interests}

The authors declare that they have no competing interests.

\section{Authors' contributions}

All authors designed the study. CB, CM, MKR, MRSV and RJ drafted the manuscript. CM and MAGDB carried out the molecular genetic studies. RJ provided the Talpa occidentalis embryonic specimens. All authors contributed to the manuscript. All authors read and approved the final manuscript.

\section{Acknowledgements}

We thank the Swiss National Fund (SNF31003A 133032/1), the Spanish Ministry of Science (CGL2004-00863/BOS and CGL2008-00928/BOS), the Andalusian Government (CVI2057), the Smart Mix Program of The

Netherlands Ministry of Economic Affairs and The Netherlands Scientific Organization for financial support. We are also grateful to C. Zollikofer and N. Morimoto, Zurich, who made available the micro-CT facilities and supervised 
their use. We thank N. Fröbisch, Berlin, and V. Weisbecker, Brisbane, for helpful comments on the manuscript.

\section{Author details}

${ }^{1}$ Paläontologisches Institut und Museum, Universität Zürich, Karl-Schmid-Strasse 4, Zürich 8006, Switzerland. ${ }^{2}$ RIKEN Center for Developmental Biology, Laboratory for Evolutionary Morphology, 2-2-3 Minatojima-minamimachi, Chuo-ku, Kobe, Hyogo 650-0047, Japan. ${ }^{3}$ Institute of Biology, University of Leiden, Sylviusweg 72, Leiden, BE 2333, The Netherlands. ${ }^{4}$ Departamento de Genética, Universidad de Granada, Avenida del Conocimiento, Granada, Armilla 18100, Spain.

Received: 24 May 2012 Accepted: 4 July 2012

Published: 9 August 2012

\section{References}

1. Asher RJ, Helgen KM: Nomenclature and placental mammal phylogeny. BMC Evol Biol 2010, 10:102.

2. Slonaker JR: Some morphological changes for adaptation in the mole. J Morphol 1920, 34:335-365.

3. Sánchez-Villagra MR, Menke PR: The mole's thumb - evolution of the hand skeleton in talpids (Mammalia). Zoology 2005, 108:3-12.

4. Mitgutsch C, Richardson MK, Jiménez R, Martin JE, Kondrashov P, de Bakker MAG, Sánchez-Villagra MR: Circumventing the polydactyly 'constraint': the mole's thumb. Biol Letters 2012, 8:74-77.

5. Meredith RW, Janecka JE, Gatesy J, Ryder OA, Fisher CA, Teeling EC, Goodbla A, Eizirik E, Simão TLL, Stadler T, Rabosky DL, Honeycutt RL, Flynn JJ, Ingram CM, Steiner C, Williams TL, Robinson TJ, Burk-Herrick A, Westerman M, Ayoub NA, Springer MA, Murphy WJ: Impacts of the Cretaceous terrestrial revolution and KPg extinction on mammal diversification. Science 2011, 334:521-524.

6. Mitgutsch C, Richardson MK, de Bakker MAG, Jiménez R, Martín JE, Kondrashov P, Sánchez-Villagra MR: From Clone to Bone: the Synergy of Morphological and Molecular Tools in Palaeobiology. In A molecularmorphological study of a peculiar limb morphology: the development and evolution of the mole's 'thumb'. Edited by Asher RJ, Müller J.: Cambridge University Press; In press.

7. Klingenberg CP: There's something afoot in the evolution of ontogenesis. BMC Evol Biol 2010, 10:221.

8. Adams DC, Nistri A: Ontogenetic convergence and evolution of foot morphology in European cave salamanders (Family: Plethodontidae). BMC Evol Biol 2010, 10:1-10.

9. Richardson MK, Gobes SMH, van Leuwen AC, Polman JAE, Pieau C, SánchezVillagra MR: Heterochrony in limb evolution: developmental mechanisms and natural selection. J ExpZool 2009, 312B:639-664

10. Sears KE: Differences in the timing of prechrondrogenic limb development in mammals: the marsupial-placental dichotomy resolved. Evolution 2009, 63:2193-2200

11. Hugi J, Hutchinsin MN, Sánchez-Villagra MR: Heterochronic shifts in the ossification sequences of surface and subsurface-dwelling skinks are correlated with the degree of limb reduction. Zoology 2012, 115:188-198.

12. Bininda-Emonds ORP, Jeffery JE, Sánchez-Villagra MS, Hanken J, Colbert M, Pieau C, Selwood L, ten Cate C, Raynaud A, Osabutey CK, Richardson MK: Forelimb-hindlimb developmental timing changes across tetrapod phylogeny. BMC Evol Biol 2007, 7:182.

13. Weisbecker V, Goswami A, Wroe S, Sánchez-Villagra MR: Ossification heterochrony in the therian postcranial skeleton and the marsupialplacental dichotomy. Evolution 2008, 62:2027-2041.

14. Richardson MK: Vertebrate evolution: the developmental origins of adult variation. BioEssays 1999, 21:604-613.

15. Fröbisch NB: Ossification patterns in the tetrapod limb - conservation and divergence from morphogenetic events. Biol Rev 2008, 83:571-600.

16. Smith KK: Sequence heterochrony and the Evolution of Development. J Morphol 2002, 252:82-97.

17. Weisbecker $\mathrm{V}$ : Monotreme ossification sequences and the riddle of mammalian skeletal development. Evolution 2011, 65:1323-1335.

18. Blanco MJ, Misof BY, Wagner GP: Heterochronic differences of Hoxa11 expression in Xenopusfore- and hind limb development: evidence for lower limb identity of the anuran ankle bones. Dev Genes Evol 1998, 208:175-187.
19. Mackem S, Mahon KA: Ghox-7: a chick homeobox gene expressed primarily in the limb buds with limb-type differences in expression. Development 1991, 113:791-806.

20. Kamiyama N, Seki R, Yokoyama H, Tamura K: Heterochronically early decline of Hox expression prior to cartilage formation in the avian hindlimb zeugopod. Dev Growth Differ 2012, 54: 619-632.

21. Smith KK: Craniofacial development in marsupial mammals: developmental origins of evolutionary change. Dev Dyn 2006, 235:1181-1193.

22. Sánchez-Villagra MR, Goswami A, Weisbecker V, Mock O, Kuratani S: Conserved relative timing of cranial ossification patterns in early mammalian evolution. Evol Dev 2008, 10:519-530.

23. Jernvall J, Thesleff I: Reiterative signaling and patterning during mammalian tooth morphogenesis. Mech Dev 2000, 92:19-29.

24. Kassai Y, Munne P, Hotta Y, Penttilä E, Kavanagh K, Ohbayashi N, Takada S, Thesleff I, Jernvall J, Itoh N: Regulation of Mammalian tooth cusp patterning by ectodin. Science 2005, 309:2067-2070.

25. Harjunmaa E, Kallonen A, Voutilainen M, Hämäläinen K, Mikkola ML, Jernvall $\mathrm{J}$ : On the difficulty of increasing dental complexity. Nature 2012, 483:324-327.

26. Chipman AD, Haas A, Tchernov E, Khaner O: Variation in anuran embryogenesis: differences in sequence and timing of early developmental events. J Exp Zool 2000, 288:352-365.

27. Mitgutsch C, Olsson L, Haas A: Early embryogenesis in discoglossoid frogs: a study of heterochrony at different taxonomic levels. J Zool Syst Evol Res 2009, 47:248-257.

28. Weisbecker V, Mitgutsch C: A large-scale survey of heterochrony in anuran cranial ossification patterns. J Zool Syst Evol Res 2010, 48:332-347.

29. Werneburg I, Sánchez-Villagra MR: The early development of the Echidna, Tachyglossus aculeatus (Mammalia: Monotremata) and the Grundmuster of mammalian development. Acta Zool-Stockholm 2011, 92:75-88.

30. Chimal-Monroy J, Rodriquez-Leon J, Montero JA, Ganan Y, Macias D, Merino $\mathrm{R}$, Hurle JM: Analysis of the molecular cascade responsible for mesodermal limb chondrogenesis: Sox genes and BMP signaling. Dev Biol 2003, 257:292-301

31. Bi W, Deng JM, Zhang Z, Behringer RR, de Crombrugghe B: SOX9 is required for cartilage formation. Nat Genet 1999, 22:85-89.

32. Akiyama H, Chaboissier MC, Martin JF, Schedl A, de Crombrugghe B: The transcription factor SOX9 has essential roles in successive steps of the chondrocyte differentiation pathway and is required for expression of Sox5 and Sox6. Gene Dev 2002, 16:2813-2828.

33. Lorda-Diez Cl, Montero JA, Diaz-Mendoza MJ, Garcia-Porrero JA, Hurle JM: Defining the earliest transcriptional steps of chondrogenic progenitor specification during the formation of the digits in the embryonic limb. PLoS One 2011, 6:e24546.

34. Welten MCM, Verbeek FJ, Meijer AH, Richardson MK: Gene expression and digit homology in the chicken embryo wing. Evol Dev 2005, 7:18-28.

35. Sears KE: Novel insights into the regulation of limb development from 'natural' mammalian mutants. BioEssays 2011, 33:327-331.

doi:10.1186/2041-9139-3-16

Cite this article as: Bickelmann et al: Transcriptional heterochrony in talpid mole autopods. EvoDevo 2012 3:16

\section{Submit your next manuscript to BioMed Central and take full advantage of:}

- Convenient online submission

- Thorough peer review

- No space constraints or color figure charges

- Immediate publication on acceptance

- Inclusion in PubMed, CAS, Scopus and Google Scholar

- Research which is freely available for redistribution 